\title{
DIÁlOGO E ACOLHIMENTO: O PROJETO ESCOLA DA FAMÍLIA E A CONSTRUÇÃO DE NOVAS RELAÇÕES COMUNITÁRIAS NO CONTEXTO PANDÊMICO
}

\section{DIALOGUE AND WELCOMING: THE FAMILY SCHOOL PROJECT AND THE CONSTRUCTION OF NEW COMMUNITY RELATIONS IN THE PANDEMIC CONTEXT}

\author{
Emanuel Mota Silveira Souto ${ }^{1}$ \\ Universidade Federal de Pernambuco - Centro Acadêmico de Vitória, PE, Brasil \\ Léa Ribeiro Silva ${ }^{2}$ \\ Rede Municipal de Ensino do Paulista, PE, Brasil \\ Valdenize Honório da Silva ${ }^{3}$ \\ Rede Municipal de Ensino do Paulista, PE, Brasil
}

\begin{abstract}
Resumo: O presente estudo concentra-se na descrição do Projeto Escola da Família e análise dos movimentos empreendidos para ajustá-lo à nova dinâmica escolar, imposta pela pandemia do Coronavírus. Constituem focos de observação as ações executadas no âmbito do projeto, com objetivo de ampliar e consolidar as relações entre a escola e sua comunidade. Destaca-se também a intenção de compreender o modelo escolar transitório e de socializar as experiências, na perspectiva de contribuir para a construção de novo paradigma educacional. A pesquisa foi realizada obedecendo a padrões metodológicos qualitativos, que possibilitam ampla integração entre os seus sujeitos e ambiente de intervenção. O projeto encontrou terreno fértil, nesses tempos pandêmicos, para fomentar o diálogo, o acolhimento, a solidariedade e a integração. O número de famílias engajadas, o teor dos diálogos, as conexões estabelecidas e as ações desencadeadas são aspectos que dimensionam o alcance e efetividade da iniciativa.

Palavras-chave: Relação família/escola; Competências socioemocionais; Ensino remoto.
\end{abstract}

\begin{abstract}
The present study focuses on the description of the Family School Project and analysis of the movements undertaken to adjust it to the new school dynamics, imposed by the Coronavirus pandemic. Observations are the actions carried out within the scope of the project, with the objective of expanding and consolidating the relations between the school and community. It also highlights the intention to understand the transitional school model and to socialize the experiences, in the perspective of contributing to the construction of a new educational paradigm. The research was carried out according to qualitative methodological standards, which allow for broad integration between its subjects and the intervention environment. The project found fertile ground, in these pandemic times, to foster dialogue, acceptance, solidarity and integration. The number of families engaged, the content of the dialogues, the connections established and the actions triggered are aspects that measure the scope and effectiveness of the initiative.
\end{abstract}

Keywords: Family / school relationship; Socio-emotional competences; Remote teaching.

\footnotetext{
${ }^{1}$ Doutorando em Educação Matemática e Tecnológica pela Universidade Federal de Pernambuco (UFPE), professor Adjunto do Núcleo de Biologia do Centro Acadêmico de Vitória da Universidade Federal de Pernambuco. E-MAIL: emanuel.silveira@ufpe.br.

${ }^{2}$ Professora da Rede Municipal de Ensino do Paulista. E-MAIL: lea.ribeiro0877@gmail.com.

${ }^{3}$ Professora da Rede Municipal de Ensino do Paulist. E-MAIL: valdenizehonorio@gmail.com.

Revista Tópicos Educacionais, Pernambuco, v. 27, n. 01, p. 120-136, 2021. ISSN: 2448-0215. https://periodicos.ufpe.br/revistas/topicoseducacionais/index

Dossiê "Conflitos, violências, bullying na escola: problemas da convivência potencializado pela pandemia?" DOI: 10.51359/2448-0215.2021.250275
} 


\title{
Introdução
}

\section{A Pandemia e o desafio de fazer com que a escola resista reexista/resista}

Nunca ficou tão evidente, quanto no contexto estabelecido pela pandemia da COVID-19, a importância da integração entre família e escola para garantir a efetividade, dentro do possível, dos processos de ensino e aprendizagem. Estabelecimento de novos vínculos, criação de canais de comunicação alternativos, reestruturação das formas de acompanhamento do desempenho discente e o diálogo permanente entre educadores e responsáveis figuram como aspectos que permeiam essa leitura.

O distanciamento social exigido, para controlar as taxas de disseminação do Coronavírus, inviabilizou a escola com sua natureza gregária e vem funcionando como agente catalisador no processo definição de um novo paradigma, marcado pela inserção das Tecnologias Digitais da Informação e Comunicação (TDIC), novas metodologias nas rotinas pedagógicas e movimentos de aproximação, mesmo que virtual, entre os membros da comunidade escolar.

No entanto, o modelo remoto vigente representa a alternativa possível e temporária, produzida em um contexto marcado por restrições sanitárias, muitas incertezas e, especificamente no Brasil, ausência de medidas efetivas para o controle das infecções e redução dos efeitos secundários. Na mesma direção do que propõe Hodges e colaboradores (2020).

\begin{abstract}
Em contraste com as experiências que são planejadas desde o início e projetadas para serem online, o ensino remoto de emergência (ERT) é uma mudança temporária de ensino para um modo de ensino alternativo devido a circunstâncias de crise. Envolve o uso de soluções de ensino totalmente remotas para instrução ou educação que, de outra forma, seriam ministradas presencialmente ou como cursos combinados ou híbridos e que retornariam a esse formato assim que a crise ou emergência diminuísse. O objetivo principal nessas circunstâncias não é recriar um ecossistema educacional robusto, mas, sim, fornecer acesso temporário à instrução e suporte educacional de uma maneira que seja rápida de configurar e esteja disponível de forma confiável durante uma emergência ou crise. (HODGES, 2020, n. p.)
\end{abstract}

Saviani e Galvão (2021) coadunam com as ideias apresentadas e reforçam o sentido emergencial do modelo educacional, a partir da distinção entre a alternativa adotada pelas sistemas de ensino e a modalidade educação a distância.

Revista Tópicos Educacionais, Pernambuco, v. 27, n. 01, p. 120-136, 2021. ISSN: 2448-0215. https://periodicos.ufpe.br/revistas/topicoseducacionais/index Dossiê "Conflitos, violências, bullying na escola: problemas da convivência potencializado pela pandemia?" DOI: $10.51359 / 2448-0215.2021 .250275$ 
Revista Tópicos Educacionais

Revista do Programa de Pós-Graduação em Educação

da Universidade Federal de Pernambuco (UFPE)

A expressão ensino remoto passou a ser usada como alternativa à educação à distância (EAD). Isso porque a EAD já tem existência estabelecida, coexistindo com a educação presencial como uma modalidade distinta, oferecida regularmente. Diferentemente, o "ensino" remoto é posto como um substituto excepcionalmente adotado neste período de pandemia, em que a educação presencial se encontra interditada. (SAVIANI e GALVÃO, 2021, p.38)

Precisamos reconhecer o esforço de fazer com que a escola não desapareça da vida das crianças, especialmente das mais vulneráveis. As inciativas pedagógicas, individuais e coletivas, que afloraram e ainda persistem em todo território nacional, ratificam o compromisso político de muitos profissionais com a tarefa educativa. Mesmo que não haja evidências da eficiência e efetividade do que vem sendo feito, assim como nenhuma garantia de que no futuro as práticas "pré-pandêmicas" voltem a assombrar a escola, precisamos estar atentos a esse mundo novo e transitório e somar forças para reconfiguração dos modelos educacionais pós-pandemia (GATTI, 2020).

Ainda no campo das novas percepções conjunturais, constatamos que a desigualdade social, legitimada e robustecida historicamente pelo sistema escolar (BOURDIEU, 1992), está em franca expansão e passou também a se materializar por meio das diferenças de acesso à internet e artefatos tecnológicos, dos níveis de violência doméstica e dos efeitos decorrentes do descompasso entre a escolarização dos responsáveis e as demandas de acompanhamento das atividades pedagógicas assíncronas.

Vale também destacar que, de acordo com o relatório Global Status Report on Preventing Violence Against Children (OMS, 2020), o fechamento das escolas tem sido considerado um fator determinante para o aumento da violência infantil e ciberbullying. Desdobramentos que têm relação direta com a compulsória hiper convivência familiar e maior circulação dos estudantes nos ambientes digitais, em função da virtualização das atividades escolares. O que vem demandando, aos responsáveis pela gestão educacional, atenção especial para esses fenômenos e o desenvolvimento de estratégias de mitigação de suas consequências.

O contexto descrito reforça a importância de que sejam somados esforços no sentido de compreender os desafios, superar as limitações históricas e as que emergiram, em função da pandemia, e avançar fazendo com que a escola, enquanto espaço de transformação de destinos, resista/reexista.

Revista Tópicos Educacionais, Pernambuco, v. 27, n. 01, p. 120-136, 2021. ISSN: 2448-0215. https://periodicos.ufpe.br/revistas/topicoseducacionais/index Dossiê "Conflitos, violências, bullying na escola: problemas da convivência potencializado pela pandemia?" DOI: $10.51359 / 2448-0215.2021 .250275$ 


\section{O percurso do Projeto Escola da Família e os movimentos de adaptação à escola possível}

O projeto foi concebido como alternativa pela gestão educacional da Rede Municipal de Ensino do Paulista, município da Região Metropolitana do Recife, para ampliar os canais de diálogo entre as famílias e profissionais em educação, fortalecer os vínculos comunitários e orientar a realização de práticas comprometidas com o desenvolvimento de competências socioemocionais.

A iniciativa foi delineada por técnicos da Secretaria Municipal de Educação, no âmbito da Gerência de Apoio Discente e Articulação Comunitária, e representantes das equipes gestoras, assumindo como premissa a necessidade de ampliar e consolidar as relações da comunidade escolar, a partir da criação de um conjunto sistemático de ações com potencial para apoiar as famílias e profissionais em educação na construção de uma nova cultura institucional, pautada no diálogo, colaboração e formação integral.

Além de contribuir para a ressignificação do papel da família no contexto escolar, o projeto assumiu a configuração de espaço formativo, à medida que permitia o desenvolvimento de temas de interesse pedagógico e os seus resultados eram socializados e alcançavam as demais escolas da rede.

Para composição dos focos temáticos, foi considerada a necessidade de conectar as práticas escolares e as rotinas familiares com o objetivo de viabilizar experiências comprometidas com desenvolvimento socioemocional dos estudantes. Uma opção completamente ajustada ao processo de implementação da Base Nacional Comum Curricular - BNCC (2018) e que reforça a urgência de superarmos a leitura dicotômica entre emoção e cognição. Condição que, como bem define Leite (2012), contribuiu para que a dimensão afetiva permanecesse historicamente no campo periférico dos espaços de ensino e aprendizagem.

O Projeto Escola da Família começou no ano letivo de 2018, com ações de mobilização para toda a rede de ensino e implementação de um conjunto de intervenções sistemáticas em 05 unidades escolares. Como existiam poucas referências de atividades com natureza similar, optouse pela construção coletiva de um repertório de estratégias, a partir das visitas realizadas nas escolas, do diálogo permanente com as famílias, atividades formativas com os profissionais em educação e da avaliação das experiências. O projeto ganhou forma e vigor ao assumir compromisso com o fortalecimento dos vínculos afetivos e com reconfiguração de práticas históricas, que só promoviam o distanciamento entre famílias e escolas.

Revista Tópicos Educacionais, Pernambuco, v. 27, n. 01, p. 120-136, 2021. ISSN: 2448-0215. https://periodicos.ufpe.br/revistas/topicoseducacionais/index Dossiê "Conflitos, violências, bullying na escola: problemas da convivência potencializado pela pandemia?" DOI: $10.51359 / 2448-0215.2021 .250275$ 
No ano letivo de 2019, o projeto foi ampliado para 11 campos de intervenção e incorporou as ações vinculadas ao Programa Melhoria da Educação, desenvolvido pelo Itaú Social em parceria com a Avante. Essa nova estrutura estava comprometida com delineamento de uma tecnologia, centrada na relação escola e comunidade e pautada nas necessidades de ampliar o conhecimento sobre as famílias, de criar canais de diálogo e escuta para todos os representantes da comunidade educativa, de instrumentalizar a participação e de fortalecer os vínculos, na perspectiva de impactar positivamente na aprendizagem das crianças e jovens.

No cenário imposto pela pandemia, mais especificamente a partir de março de 2020, o esforço do Projeto Escola da Família precisou ser ampliado e redirecionado. Afinal, não havia mais a possibilidade de realizar os encontros presenciais, nem as visitas de acompanhamento e as rodas diálogo com trocas diretas, olho no olho. Nos primeiros meses da suspensão das atividades escolares, concentramos nossa força de trabalho no sentido de apoiar as ações emergenciais definidas em rede, entre elas: a construção de diretrizes pedagógicas para o ensino remoto, organização da distribuição de atividades impressas e kits de alimentação escolar, estabelecimento do currículo prioritário e criação dos espaços virtuais para atividades pedagógicas e formativas.

Estabelecida um ordenamento, dentro do possível, para o funcionamento das unidades escolares o projeto pode assumir um novo formato, recalcular sua rota, reeditar suas ações e ocupar novos lugares nessa escola transitória, desafiadora e carente de práticas comprometidas com o acolhimento. Essa transformação constitui a base de observação e reflexão deste estudo, sendo apresentada nas seções que seguem com a intenção de socializar as experiências e reforçar a importância de envidar esforços para a construção de novo projeto de sociedade, educação e escola. Um projeto único, integrado, cheio de intencionalidade e que vai, à medida que o corpo toma forma, sendo reeditado e retroalimentando a força de quem o constrói. Algo capaz de resgatar o sentido ontológico da utopia e mobilizar sempre novos passos em direção a um horizonte em que predominem a justiça social, o respeito às singularidades e a empatia.

\section{Metodologia}

Os princípios metodológicos adotados validam a opção pela abordagem qualitativa, que caracteriza este estudo, reconhecendo a necessidade da superação de um modelo que a coloca em

Revista Tópicos Educacionais, Pernambuco, v. 27, n. 01, p. 120-136, 2021. ISSN: 2448-0215. https://periodicos.ufpe.br/revistas/topicoseducacionais/index Dossiê "Conflitos, violências, bullying na escola: problemas da convivência potencializado pela pandemia?" DOI: $10.51359 / 2448-0215.2021 .250275$ 
condição oposta à pesquisa quantitativa e aprofunda a relação entre pesquisador e objeto. Para Crewell (2007), a pesquisa qualitativa apoia-se em métodos múltiplos que são integrativos e humanísticos e que reforçam a importância do pesquisador na identificação dos elementos prioritários do estudo.

As intenções que mobilizaram o trabalho e a própria natureza do objeto direcionaram os pesquisadores para o campo da pesquisa intervenção, que se aproxima do que Tripp (2005) define como pesquisa-ação, por envolver uma tentativa sistemática de analisar e aprimorar as atividades desenvolvidas. Outros aspectos que reforçam essa categorização: 1) são pesquisas aplicadas; 2) partem de uma intenção de mudança ou inovação; 3) trabalham com dados criados, em contraposição a dados já existentes, que são simplesmente coletados; 4) envolvem uma avaliação rigorosa e sistemática dos efeitos de tais práticas.

Como campo de observação/intervenção recrutamos o conjunto de atividades desenvolvidas na reconfiguração do Projeto Escola da Família, caracterizado na seção anterior, visando ajustá-lo à nova dinâmica escolar imposta pelo distanciamento social. Nesse contexto, figuram como sujeitos da pesquisa os profissionais da Secretaria de Educação, responsáveis pela readequação e execução do projeto durante o ano letivo de 2020, membros das equipes gestoras, professores e representantes das famílias dos estudantes.

Para a captação dos dados, foram construídos instrumentos virtuais, considerando a impossibilidade de contato presencial entre os pesquisadores e os demais sujeitos da pesquisa. Assim, optou-se por questionários eletrônicos e ferramentas digitais, que permitissem os registros das impressões dos pesquisadores durante atividades realizadas, obedecendo às diretrizes metodológicas da observação participante. Estratégia que permite a exploração de todos os sentidos (FLICK, 2009) e interação permanente do pesquisador com o ambiente estudado (ANGROSINO, 2009).

Os dados obtidos foram sistematizados a partir da análise de conteúdo, seguindo as fases descritas por Bardin (2011): a) a pré-análise; b) a exploração do material; c) o tratamento dos resultados, a inferência e a interpretação. Ainda sobre a análise das informações levantadas, destacamos que foi adotado como princípio a busca pelos significados expressos, caminhando para além da descrição dos conteúdos e dados. A exploração do material produzido nos ambientes virtuais e nas atividades foi complementada por meio do registro das observações seletivas e diretas (LANKSHEAR e KNOBEL, 2008).

Revista Tópicos Educacionais, Pernambuco, v. 27, n. 01, p. 120-136, 2021. ISSN: 2448-0215. https://periodicos.ufpe.br/revistas/topicoseducacionais/index Dossiê "Conflitos, violências, bullying na escola: problemas da convivência potencializado pela pandemia?" DOI: $10.51359 / 2448-0215.2021 .250275$ 


\section{Resultados e Discussão}

O projeto, que constitui a base de análise deste estudo, construiu uma trajetória marcada pelo compromisso de criar espaços de reflexão e ação com foco na relação escola e famílias, a partir de um conjunto de ações que promoviam encontros, rodas de diálogo, visitas técnicas e momentos formativos para representantes de toda comunidade escolar. Uma experiência inovadora, centrada nas possibilidades de engajar familiares e profissionais da educação na tarefa de promover condições capazes de estimular o desenvolvimento integral dos estudantes, apostando na criação de uma rede de afetos e valorização da dimensão socioemocional de todos que integram a comunidade escolar.

As ações aconteciam em um grupo limitado de escolas, selecionadas em função dos níveis de vulnerabilidade social e manifestação prévia de interesse por parte da gestão escolar, mas as primeiras avaliações ampliadas do projeto já anunciavam a capilaridade de seus princípios, estratégias e zonas temáticas para muitas outras unidades da rede de ensino. $\mathrm{O}$ aumento da participação da família nas vivências, a redução dos jogos de transferência de responsabilidade nos discursos e a melhoria no ambiente relacional constituíam elementos mobilizadores dos movimentos de consolidação e expansão autônoma dos princípios defendidos pelos idealizadores do projeto.

Para melhor compreensão do percurso do Projeto Escola da Família e das análises dos resultados alcançados, sintetizamos, no quadro 1, suas etapas estruturantes, objetivos e cronologia.

Quadro 1 - Descrição sintética do Projeto Escola da Família

\begin{tabular}{|c|l|c|}
\hline Etapas Estruturantes & \multicolumn{1}{|c|}{$\begin{array}{c}\text { Detalhamento dos objetivos e agentes } \\
\text { envolvidos }\end{array}$} & Período \\
\hline $\begin{array}{c}\text { Formação da Equipe } \\
\text { Técnica }\end{array}$ & $\begin{array}{l}\text { Criação de um espaço de reflexão sobre o projeto } \\
\text { para definição das linhas de atuação, formação } \\
\text { da equipe técnica, identificação das prioridades e } \\
\text { análise da capacidade de realização. }\end{array}$ & $\begin{array}{c}1^{\circ} \text { Semestre } \\
2018\end{array}$ \\
\hline
\end{tabular}

Revista Tópicos Educacionais, Pernambuco, v. 27, n. 01, p. 120-136, 2021. ISSN: 2448-0215. https://periodicos.ufpe.br/revistas/topicoseducacionais/index Dossiê "Conflitos, violências, bullying na escola: problemas da convivência potencializado pela pandemia?" DOI: $10.51359 / 2448-0215.2021 .250275$ 
Revista Tópicos Educacionais

Revista do Programa de Pós-Graduação em Educação da Universidade Federal de Pernambuco (UFPE)

\begin{tabular}{|c|c|c|}
\hline $\begin{array}{l}\text { Mapeamento das } \\
\text { unidades de ensino } \\
\text { e definição de focos } \\
\text { temáticos }\end{array}$ & $\begin{array}{l}\text { Identificação das escolas que, em função das } \\
\text { particularidades e demandas, seriam atendidas no } \\
\text { primeiro ano de vigência do projeto (Intervenção } \\
\text { Piloto) e adequação temática. }\end{array}$ & $\begin{array}{c}1^{\circ} \text { Semestre } \\
2018\end{array}$ \\
\hline $\begin{array}{l}\text { Definição das linhas de } \\
\text { ação }\end{array}$ & $\begin{array}{l}\text { Construção coletiva das linhas de atuação: } \\
\text { diagnóstico das famílias, apoio à gestão escolar e } \\
\text { atividades de integração com a comunidade } \\
\text { escolar. }\end{array}$ & $\begin{array}{c}1^{\circ} \text { Semestre } \\
2018\end{array}$ \\
\hline Intervenção Piloto & $\begin{array}{l}\text { Desenvolvimento do primeiro conjunto de ações } \\
\text { sistemáticas nas unidades definidas como } \\
\text { prioritárias. }\end{array}$ & $\begin{array}{c}2^{\circ} \text { Semestre } \\
2018\end{array}$ \\
\hline $\begin{array}{l}\text { Consolidação das } \\
\text { estratégias de atuação e } \\
\text { ampliação }\end{array}$ & $\begin{array}{l}\text { Definição sistemática, a partir das experiências } \\
\text { vivenciadas e diálogo com a comunidade } \\
\text { escolar, das estratégias de atuação, instrumentos } \\
\text { de validação e mecanismos de devolutiva do } \\
\text { projeto. }\end{array}$ & $\begin{array}{l}1^{\mathrm{o}} \text { e } 2^{\mathrm{o}} \\
\text { Semestres } \\
2019\end{array}$ \\
\hline $\begin{array}{l}\text { Vinculação à } \\
\text { Tecnologia Escola } \\
\text { Comunidade }\end{array}$ & $\begin{array}{l}\text { Integração do projeto ao desenvolvimento de } \\
\text { uma tecnologia educacional centrada no } \\
\text { fortalecimento da relação escola e comunidade, } \\
\text { coordenado pela Fundação Itaú Social e Avante }\end{array}$ & $\begin{array}{c}2^{\circ} \text { Semestre } \\
2019\end{array}$ \\
\hline $\begin{array}{c}\text { Adequação do projeto à } \\
\text { dinâmica remota }\end{array}$ & $\begin{array}{l}\text { Construção de alternativas para garantir a } \\
\text { continuidade do projeto em um contexto } \\
\text { marcado pelo distanciamento social e ampliação } \\
\text { do alcance. }\end{array}$ & $\begin{array}{l}1^{\mathrm{o}} \text { e } 2^{\mathrm{o}} \\
\text { Semestres } \\
2020\end{array}$ \\
\hline
\end{tabular}

Fonte: Os autores.

O conjunto de ações mobilizou o interesse das equipes gestoras, professores e famílias, figurando como uma alternativa possível para o desenvolvimento de intervenções centradas no acolhimento, respeito às singularidades e valorização da participação coletiva.

\section{A necessidade de recalcular a rota}

Desde sua concepção, o Projeto Escola da Família se propunha a integrar a frente de ações e políticas que tinham como objetivo central ressignificar a função social da escola, revigorando o sentido de que, para além dos conteúdos, os espaços pedagógicos precisavam reconhecer seu protagonismo no desenvolvimento das competências socioemocionais dos estudantes e demais representantes da comunidade escolar. Missão alinhada à construção e implementação de uma nova proposta curricular e criação de novos ambientes de diálogo, de formação e intervenção.

Revista Tópicos Educacionais, Pernambuco, v. 27, n. 01, p. 120-136, 2021. ISSN: 2448-0215.

https://periodicos.ufpe.br/revistas/topicoseducacionais/index

Dossiê "Conflitos, violências, bullying na escola: problemas da convivência potencializado pela pandemia?" DOI: $10.51359 / 2448-0215.2021 .250275$ 
Revista Tópicos Educacionais

Em uma sociedade como a nossa, em que os alunos passam, desde a mais tenra idade, várias horas de suas vidas na escola, cabe pensar no papel do ambiente escolar na promoção da saúde mental e física dos estudantes. Uma "escola suficientemente boa", com "professores suficientemente bons" (parafraseando Winnicott) é uma alternativa institucional para combater os revezes decorrentes de condições familiares e sociais marcadas por carências afetivas, alimentares, materiais, muitas vezes envolvidas em violências de diferentes tipos e graus. (ABED, 2014, p. 112)

Com o estabelecimento da pandemia da COVID-19 e a instalação do modelo de ensino remoto emergencial, as redes precisaram se ajustar, na velocidade de crise, a essa nova realidade. Nessa direção, técnicos pedagógicos e gestores escolares foram convidados redefinir as estratégias do Projeto Escola da Família, a partir das novas demandas e inviabilidade das formas de intervenção e interação presenciais. Muito mais do que migrar do formato presencial para os ambientes virtuais, a tarefa impulsionava a construção de um novo significado para o trabalho. $\mathrm{O}$ quadro 2 traz, de forma sintética, as principais adequações promovidas nas frentes de atuação do Escola da Família.

Quadro 2 - Definição de novas frentes de atuação e detalhamento de ações.

\begin{tabular}{|l|l|}
\hline \multicolumn{1}{|c|}{$\begin{array}{c}\text { Frentes de } \\
\text { Atuação }\end{array}$} & \multicolumn{1}{c|}{ Ações Propostas } \\
\hline Comunicação & $\begin{array}{l}\text { Ampliação dos canais de comunicação direta, por meio de aplicativos } \\
\text { de mensagens e maior atuação da unidade escolar nas redes sociais; } \\
\text { Realização de pesquisa, via questionários digitais, com o intuito de } \\
\text { analisar a percepção das famílias e equipes gestoras sobre o novo } \\
\text { contexto. }\end{array}$ \\
\hline Integração & $\begin{array}{l}\text { Promoção de encontros virtuais para as famílias, pautados na escuta } \\
\text { ativa, acolhimento e construção coletiva de alternativas para o } \\
\text { acompanhamento e suporte pedagógico para os estudantes; } \\
\text { Criação de estratégias de apoio para as equipes gestoras no sentido de } \\
\text { instrumentalizar as práticas em ambientes virtuais; }\end{array}$ \\
\hline Temário & $\begin{array}{l}\text { Adequação temática, considerando os desafios da hiper convivência e } \\
\text { a urgência de mobilizar todos para o combate às diferentes formas de } \\
\text { violência, para o fortalecimento das práticas de acolhimento e para a } \\
\text { criação de estratégias de suporte pedagógico para as crianças e } \\
\text { jovens. }\end{array}$ \\
\hline Acompanhamento & $\begin{array}{l}\text { Construção de instrumentos e práticas para acompanhamento das } \\
\text { atividades, registro da produção e avaliação sistemática da }\end{array}$ \\
\hline
\end{tabular}

Fonte: Os autores.

Revista Tópicos Educacionais, Pernambuco, v. 27, n. 01, p. 120-136, 2021. ISSN: 2448-0215. https://periodicos.ufpe.br/revistas/topicoseducacionais/index Dossiê "Conflitos, violências, bullying na escola: problemas da convivência potencializado pela pandemia?" DOI: $10.51359 / 2448-0215.2021 .250275$ 
O novo direcionamento dado ao projeto tomou como base de referência as impressões dos gestores escolares envolvidos diretamente nas ações, além das diretrizes definidas pela gestão municipal para o contexto pandêmico. Entre os registros, obtidos ao longo do processo de readequação, destacamos os recortes das falas que direcionaram as alterações:

(G1) "Os pais falam, durante a entrega da merenda escolar, que as crianças sentem falta da escola, da rotina e dos professores. Estão todos muito angustiados e muitos sem perspectiva. A pandemia tirou o emprego de muita gente e as crianças sentem o sofrimento da família. Elas estão mais nervosas e irritadas." (G2) "As famílias estão precisando de ajuda. Muitos não conseguem acompanhar as crianças nas aulas virtuais e alguns relatam que tanto tempo em casa tem aumentado o estresse. O grupo do WhatsApp da escola não para.”

O posicionamento dos gestores traduz percepções quase que coletivas sobre alguns dos efeitos deletérios do modelo de ensino emergencial. Sentimentos como angústia, medo, desesperança e apatia figuram com maior frequência nos discursos de familiares e profissionais em educação. Condição amplamente justificada pelas perdas afetivas e socioeconômicas, aliadas à persistência da crise sanitária e à quase que completa ausência de políticas públicas capazes de amparar os mais vulneráveis.

O laço social entre estudantes, professores e comunidade escolar é precioso para a formação humana em nossa sociedade. A perda do convívio escolar é, sem dúvida, um dos mais impactantes e dramáticos efeitos das medidas de distanciamento social. Entendemos que a escola é (ou deve ser) uma referência nuclear da atividade social das crianças, adolescentes e suas famílias e comunidades. Em um momento de tamanho apuro da sociedade brasileira, essa instituição-referência pode funcionar como apoio, articulando-se a redes de assistência à população, buscando formas de acompanhamento dos estudantes e suas famílias, especialmente aquelas em situação de maior vulnerabilidade. (FRANCO et al., 2020, p. 2)

Ao fazer a opção explícita por práticas de acolhimento das famílias e comunidade ratificamos a importância da escola com como como lócus privilegiado para a aprendizagem e desenvolvimento humano, em suas múltiplas dimensões. Esses movimentos exigem, além da intencionalidade, planejamento, disponibilidade, empatia e compromisso com a construção de ambientais relacionais saudáveis.

\section{Ampliação do conjunto de informações sobre as famílias no contexto da pandemia.}

Para garantir intervenções institucionais mais robustas e com impactos positivos concretos na relação família e escola, a coordenação do projeto fortaleceu os espaços de escuta e diálogo, já

Revista Tópicos Educacionais, Pernambuco, v. 27, n. 01, p. 120-136, 2021. ISSN: 2448-0215. https://periodicos.ufpe.br/revistas/topicoseducacionais/index Dossiê "Conflitos, violências, bullying na escola: problemas da convivência potencializado pela pandemia?" DOI: $10.51359 / 2448-0215.2021 .250275$ 
consolidados nas redes sociais e outros canais de integração com a comunidade, e optou por utilizar um questionário eletrônico para coletar mais informações sobre as necessidades, zonas de interesse e novas leituras da atual conjuntura.

O instrumento foi lançado na rede, nos últimos quinze dias do mês de agosto de 2020, e difundido pelos gestores escolares e técnicos da secretaria por meio dos grupos existentes nos aplicativos de mensagem. O preenchimento do instrumento era voluntário e não estava restrito às escolas beneficiadas diretamente pelo projeto.

Convém destacar que o munícipio já havia criado uma força tarefa, durante o ano letivo de 2019, com a missão de construir, em parceria com a Avante - Educação e Mobilização Social, um amplo diagnóstico social e demográfico das famílias, com estudantes matriculados na rede municipal de ensino. A aplicação de novos questionários possibilitou o reforço do conjunto de informações diagnósticas, por meio da incorporação de aspectos que emergiram em um contexto disruptivo, marcado por uma transição digital compulsória, aumento das desigualdades sociais e novos arranjos pedagógicos.

Apesar das restrições quanto ao acesso à internet e de outros fatores limitantes circunstanciais, 310 famílias, de todas as 62 unidades de ensino, preencheram o questionário, contribuindo para revitalização do perfil das famílias da rede municipal de ensino, a partir da identificação de novas demandas, impressões das famílias sobre a dinâmica escolar e proposições.

O primeiro bloco de perguntas foi lançado com a intenção de coletar informações sobre conectividade, artefatos tecnológicos disponíveis e principais formas de comunicação entre a família e a escola. De acordo com a análise das respostas obtidas, 94,5\% das famílias declaram possuir acesso à internet, indicando o celular como principal instrumento para conexão. É importante destacar que temos convicção de que essa informação sobre o nível de conectividade das famílias não traduz com fidedignidade as condições necessárias para que os estudantes participem de atividades pedagógicas remotas. Essa leitura é corroborada pelos dados obtidos quando os pais ou responsáveis são questionados sobre a maior dificuldade para garantir a participação dos estudantes nas atividades remotas, conforme síntese expressa no gráfico 1.

Gráfico 1 - Limitações da participação discente nas atividades remotas

Revista Tópicos Educacionais, Pernambuco, v. 27, n. 01, p. 120-136, 2021. ISSN: 2448-0215. https://periodicos.ufpe.br/revistas/topicoseducacionais/index Dossiê "Conflitos, violências, bullying na escola: problemas da convivência potencializado pela pandemia?" DOI: $10.51359 / 2448-0215.2021 .250275$ 
Revista Tópicos Educacionais

Revista do Programa de Pós-Graduação em Educação

da Universidade Federal de Pernambuco (UFPE)

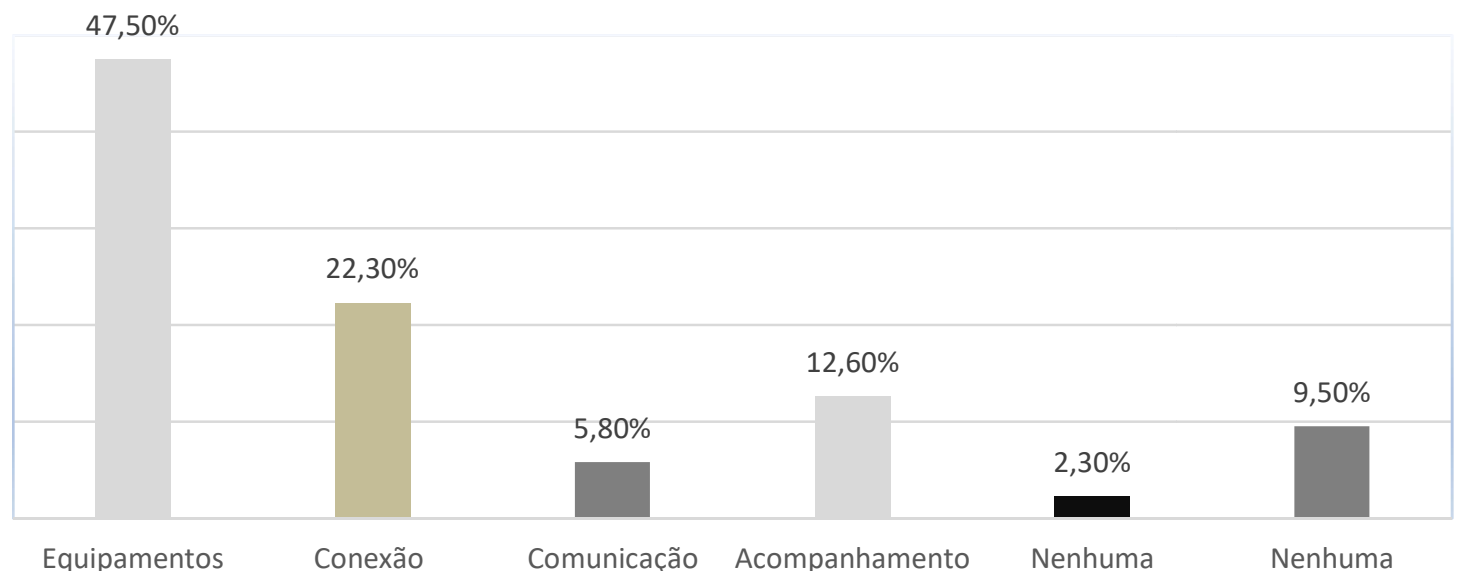

Fonte: Secretaria Municipal de Educação do Paulista

Reconhecendo a importância estratégica da comunicação com a escola para a consolidação das relações, acompanhamento remoto e mobilização da comunidade escolar, foi também solicitado às famílias que indicassem os principais meios de comunicação com a escola. As respostas obtidas colocam o aplicativo de mensagens Whatsapp ${ }^{\circledR}$ em uma posição de destaque, 94,2\% das famílias optam pela ferramenta, em detrimento das demais alternativas (outras mídias sociais, e-mail e ligações telefônicas). Consideramos que essa escolha está atrelada à presença já estabelecida do referido aplicativo no cotidiano da maioria das pessoas, o baixo consumo de dados demandado pela ferramenta e outros padrões de usabilidade.

A aplicação do questionário permitiu também identificar que a maioria das famílias respondentes $(60,3 \%)$ reconhecem que a sua relação com as unidades de ensino melhorou durante a pandemia e indicam, entre os profissionais em educação, os professores e gestores escolares como os principais agentes de interlocução. Ainda no mesmo campo da análise, propusemos uma questão em que os participantes tinham a possibilidade categorizar sua relação com a escola. $\mathrm{O}$ gráfico 2, traz a compilação das respostas e nos permite, influenciados por esse novo contexto, inferir que os esforços, empreendidos pelas escolas para melhorar os padrões de comunicação, reestruturar as estratégias de apoio aos estudantes e intensificar o diálogo com os pais ou responsáveis, já repercutem nas leituras sociais sobre a ampliação e fortalecimento dos vínculos entre os membros da comunidade escolar.

Gráfico 2 - Percepção das famílias sobre sua relação com a escola.

Revista Tópicos Educacionais, Pernambuco, v. 27, n. 01, p. 120-136, 2021. ISSN: 2448-0215. https://periodicos.ufpe.br/revistas/topicoseducacionais/index Dossiê "Conflitos, violências, bullying na escola: problemas da convivência potencializado pela pandemia?" DOI: $10.51359 / 2448-0215.2021 .250275$ 
Fonte: Secretaria Municipal de Educação do Paulista

O desafio de coletar mais informações sempre esteve associado à ideia de organizar e estruturar as ações implementadas da rede municipal de ensino. Esses movimentos foram reforçados inclusive pela praticidade, diversidade e popularização das ferramentas tecnológicas digitais. As famílias, para acompanhar e apoiar os estudantes nas atividades remotas, foram estimuladas a desenvolver novas competências digitais e habilidades que as permitissem compreender a dinâmica das salas virtuais e outras vias recrutadas pedagogicamente para garantir a persistência da escola.

\section{A importância de estender as ideias de acolhimento pela Escola da Família para todos.}

Com um lastro experiencial consolidado, validação da comunidade escolar, apoio sistemático dos parceiros institucionais e capacidade de alcance ampliada pelas TIDC, o Projeto Escola da Família foi estendido para todas as escolas. Abranger toda rede de ensino já figurava como uma meta do projeto que foi, de certa forma, catalisada pelo contexto pandêmico.

Nesse sentido, foram desenvolvidas estratégias de mobilização com a intenção de informar e sensibilizar toda comunidade escolar para a importância do apoio mútuo e a revitalização do sentido político e existencial das experiências promovidas pelas escolas. Peças digitais foram criadas e socializadas, via aplicativos de mensagens e outras mídias sociais, gestores foram orientados a reforçar os convites para os momentos de integração e a coordenação do projeto

Revista Tópicos Educacionais, Pernambuco, v. 27, n. 01, p. 120-136, 2021. ISSN: 2448-0215. https://periodicos.ufpe.br/revistas/topicoseducacionais/index Dossiê "Conflitos, violências, bullying na escola: problemas da convivência potencializado pela pandemia?" DOI: $10.51359 / 2448-0215.2021 .250275$ 
estabeleceu um cronograma de encontros virtuais, que congregava escolas com perfis comunitários semelhantes.

O trabalho de mobilização prévia demandou disponibilidade dos interlocutores e capacidade para identificar agentes na comunidade escolar com potencial para dialogar de forma direta com público-alvo. Nessa etapa, o desafio concentrava-se na necessidade de explicitar a importância da participação coletiva e anunciar previamente temas e focos das atividades integradoras.

Criar espaços de diálogo com as famílias e profissionais em educação, em um momento tão conturbado, não pode ser considerada uma tarefa trivial. E fazer isso em escala ampliada e com mediação via TDIC, torna essa ação ainda mais desafiadora e instigante. Isso porque até então todos os encontros do projeto, atividades de acompanhamento e momentos de análise de resultados aconteciam de forma presencial, com a escola em pleno funcionamento.

O distanciamento social impactou profundamente nas formas de interação entre os membros da comunidade educativa. $\mathrm{O}$ trabalho remoto dos professores com estudantes também teve caráter pedagógico para os pais/responsáveis que, em muitos casos, precisaram desenvolver novas competências, inclusive digitais, para acompanhar as atividades síncronas e assíncronas propostas em ambientes virtuais. Esse novo capital, ainda em expansão, foi fundamental para garantir a ampla participação das famílias nas ações do projeto e reverbera também no desempenho pedagógico das crianças e jovens.

As vivências do Projeto Escola da Família, em sua nova formatação, reforçam o valor da iniciativa institucional para a consolidação dos vínculos e estabelecimento de novas conexões. O espaço de diálogo e reflexão possibilitou o posicionamento das famílias e profissionais que relatavam suas angústias, cobravam a presença e responsabilidade do Estado, expressavam suas perdas, descreviam seus medos e, principalmente, traziam exemplos de superação, solidariedade e empatia. É importante também ressaltar que os encontros constituíram uma frente importante no combate à violência em suas diferentes formas, evasão escolar e esclarecimento sobre a necessidade das medidas sanitárias preventivas.

O desenvolvimento de atividades com ampla participação das famílias ratificou a ideia de que é fundamental que a escola realize e incorpore a escuta sensível da comunidade, para além dos aspectos pedagógicos. Nesse sentido, merecem destaque os temas escolhidos para os encontros e

Revista Tópicos Educacionais, Pernambuco, v. 27, n. 01, p. 120-136, 2021. ISSN: 2448-0215. https://periodicos.ufpe.br/revistas/topicoseducacionais/index Dossiê "Conflitos, violências, bullying na escola: problemas da convivência potencializado pela pandemia?" DOI: 10.51359/2448-0215.2021.250275 
as estratégias metodológicas adotadas, considerados fatores determinantes para gerar o engajamento tanto das famílias, quanto dos profissionais em educação.

A análise colegiada das devolutivas produzidas pelas equipes gestoras reforça também o alcance da função formativa e o caráter sustentável do projeto, que desde a sua concepção priorizava a autonomia e o protagonismo da escola na construção da sua relação com a comunidade. Nesse sentido, as intervenções mediadas pelos representantes da Secretaria de Educação foram adotadas como referência para o planejamento e execução de outras atividades integradoras, com intencionalidade, método e abordagem temática dentro das linhas propostas pela Escola da Família.

\section{Conclusão}

Acolher é um dos mais genuínos exercícios empáticos e temos a oportunidade de reaprender, com todas as impossibilidades, dores e medos contemporâneos, a importância de estimular essas práticas no ambiente escolar. Como já dissemos, precisamos resgatar o sentido ontológico do fazer educação, à medida que avançamos na construção de novos significados para escola, suas relações e fazeres.

O Projeto Escola da Família encontrou terreno fértil, nesses tempos pandêmicos, para fomentar o diálogo, o acolhimento, a solidariedade e a integração. O número de famílias engajadas nas ações virtuais, o teor dos diálogos, as conexões estabelecidas e as ações desencadeadas são aspectos que dimensionam o alcance e efetividade do projeto.

A nossa intenção é de que os princípios e valores difundidos sejam incorporados em uma nova cultura institucional e que as unidades de ensino assumam o protagonismo nos processos integração com sua comunidade. Acreditamos que o ensino remoto é uma opção transitória e que todo esse contexto está atuando como catalisador de um processo de transformação escolar ansiado e defendido.

Nada o que propusemos é inédito ou novo, temos apenas o registro de mais uma iniciativa que prova, a partir de sua materialização, que é complemente possível conceber e realizar uma escola, que vá além da transmissão de conteúdos e supere o padrão burocrático de relação com sua comunidade. Uma escola que se reconheça como local privilegiado para o desenvolvimento socioemocional dos todos.

Revista Tópicos Educacionais, Pernambuco, v. 27, n. 01, p. 120-136, 2021. ISSN: 2448-0215. https://periodicos.ufpe.br/revistas/topicoseducacionais/index Dossiê "Conflitos, violências, bullying na escola: problemas da convivência potencializado pela pandemia?" DOI: $10.51359 / 2448-0215.2021 .250275$ 


\section{Referências}

ABED, Anita. O desenvolvimento das habilidades socioemocionais como caminho para a aprendizagem e o sucesso escolar de alunos da educação básica. São Paulo: UNESCO/MEC, 2014

ANGROSINO, Michael. Etnografia e observação participante. Porto Alegre: Artmed, 2009.

BARDIN, Laurence. Análise de conteúdo. São Paulo: Edições 70, 2011.

BORDIEU, P. A reprodução. Rio de Janeiro: Francisco Alves, 1992.

CUNHA, Marcus Vinícius. A escola contra a família. In: LOPES, E.M.T.; FARIA FILHO, L.M.; VEIGA, Cyntia Greive (Org.). 500 anos de educação no Brasil. 5.ed. Belo Horizonte: Autêntica, 2011.

CRESWELL. John. Projeto de pesquisa: Métodos qualitativo, quantitativo e misto. 2ed. Porto Alegre. 2007.

BRASIL. Base Nacional Comum Curricular : documento de caráter mandatório que orienta a formulação dos currículos escolares. Brasília, DF: Ministério da Educação, 2018.

GATTI, Bernadete Angelina. Possível reconfiguração dos modelos educacionais pós-pandemia. Estudos Avançados, v. 34, n. 100, p. 29-41, 2020.

FLICK, Uwe. Introdução à pesquisa qualitativa ; tradução. Joice Elias Costa. - 3. ed. - Porto Alegre : Artmed, 2009.

FRANCO, Adriana Fátima et al. Ponderações sobre o ensino escolar em tempos de quarentena: carta às professoras e professores brasileiros. 2020. Disponível em: http://cev.org.br/biblioteca/ponderacoessobreoensinoescolaremtemposdequarentenacartaasprofessoraseprofessores-brasileiros/ . Acesso em: 04 de abril de 2021.

HODGES, Charles et al. The difference between emergency remote teaching and online learning. EDUCAUSE Review. 27 mar. 2020. Disponível em: https://er.educause.edu/articles/2020/3/thedifference-between-emergency-remote-teaching-and-online-learning , 2020. Acesso em: 15 de abril de 2021.

LANKSHEAR C.; KNOBEL M. Pesquisa pedagógica. Do projeto à implementação. Porto Alegre. Artmed. 2008.

LEITE, S. A. Afetividade nas práticas pedagógicas. Temas em Psicologia, Ribeirão Preto, v.20, n. 2, p. 355-368, 2012.

Revista Tópicos Educacionais, Pernambuco, v. 27, n. 01, p. 120-136, 2021. ISSN: 2448-0215. https://periodicos.ufpe.br/revistas/topicoseducacionais/index Dossiê "Conflitos, violências, bullying na escola: problemas da convivência potencializado pela pandemia?" DOI: $10.51359 / 2448-0215.2021 .250275$ 
Revista Tópicos Educacionais

Revista do Programa de Pós-Graduação em Educação

da Universidade Federal de Pernambuco (UFPE)

OMS. Global Status Report on Preventing Violence Against Children, Genebra, 2020.

Disponível em: https://www.end-violence.org/articles/global-status-report-preventing-violenceagainst-children-2020. Acesso em: 16 de abril de 2020 .

SAVIANI, D.; GALVÃO, A. C. "Educação na Pandemia: a falácia do "ensino remoto". Universidade e Sociedade ANDES-SN, ano XXXI, janeiro, 2021.

TRIPP, David. Pesquisa-ação: uma introdução metodológica. Educação e Pesquisa, São Paulo, v. 31, n. 3, set./dez. 2005.

Recebido em maio de 2021.

Aprovado em junho de 2021.

Revista Tópicos Educacionais, Pernambuco, v. 27, n. 01, p. 120-136, 2021. ISSN: 2448-0215.

https://periodicos.ufpe.br/revistas/topicoseducacionais/index

Dossiê "Conflitos, violências, bullying na escola: problemas da convivência potencializado pela pandemia?" DOI: $10.51359 / 2448-0215.2021 .250275$ 